\title{
Competence of Teacher in Making e-LKPD Using Flip Book Maker with Emphasis on Macro, Submicro, and Simbolic Level Representation of Chemistry
}

\author{
Minda Azhar*1 ${ }^{1}$, Alizar ${ }^{1}$, Miftahul Khair ${ }^{1}$, Ranny $^{1}$, Nadya Dewara ${ }^{1}$, Dika Adriani ${ }^{1}$, \\ Zulhendra ${ }^{2}$ \\ ${ }^{1}$ Jurusan Kimia, Fakultas MIPA, Universitas Negeri Padang, Air Tawar Barat, Kota Padang, 25171, Indonesia \\ ${ }_{2}^{2}$ Jurusan Elektronika, Fakultas Teknik, Universitas Negeri Padang, Air Tawar Barat, Kota Padang, 25171, \\ Indonesia \\ *Correspondence: minda@fmipa.unp.ac.id; Tel.:0751-57420106
}

Diterima 22 Oktober 2019, Disetujui 3 Januari 2020. Dipublikasikan 31 Maret 2020

\begin{abstract}
The aim of the Community Partnership Program (PKM) service activity is to increase teacher competency in making electronic electronic Student Work Sheets (e-LPKD) using flip book makers with an emphasis on three levels of chemical representation. The method used is lectures, demonstrations and workshops. The lecture and demonstration methods are used to deliver the topics i.e ICT and internet terminology, industrial revolution 4 and three levels of chemical representation. The practice includes quick tricks of editing images from general chemistry books and transferring them to LKPD. Workshops are to make eLKPD using a flip book maker accompanied by videos of learning chemistry, animation of chemical concepts. This activity can improve the knowledge and skills of chemistry teachers using standard general chemistry e-books, videos of chemistry learning and chemical animation from internet. This community service activities can improve the knowledge and skills of chemistry teachers in integrating a variety of learning resources that can be used to create ICT-based e-LKPD by emphasizing on three levels of chemical representation.
\end{abstract}

Keywords : macroscopic representation, submicroscopic representation, symbolic representation, eLKPD, ICT

This is an open access article distributed under the Creative Commons 4.0 Attribution License, which permits unrestricted use, distribution, and reproduction in any medium, provided the original work is properly cited. $(2020$ by author

Pada era revolusi industri 4.0 , perkembangan teknologi telekomunikasi termasuk jaringan komputer sangat cepat. Berbagai teknologi dan aplikasi pendukung keilmuan berkembang pada berbagai bidang termasuk bidang pendidikan dan pengajaran. Perkembangan ini merupakan sumber potensial pembelajaran kimia yang dapat dimanfaatkan pada pembuatan e-LKPD dengan penekanan pada tiga level representasi kimia oleh guru-guru kimia. Selain itu, e-LKPD tersebut dapat dilengkapi dengan vidio pembelajaran, animasi, musik serta dapat didownload siswa.

SMAN Kabupaten Padang Pariaman yang bergabung pada MGMP guru kimia berjumlah 23 buah sekolah dengan guru kimia yang aktif di MGMP sekitar 25-30 orang. Pada setiap sekolah tersedia laboratorium komputer dan fasilitas internet. Dengan kata lain, SMAN di Kabupaten Padang Pariaman telah melengkapi diri dengan fasilitas Information and Communication Technology (ICT) guna 
mendukung proses belajar mengajar yang berkualitas.

ICT diperlukan untuk pelaksanaan kurikulum 2013 yang lebih baik. Salah satu kegunaannya adalah untuk membuat electronic-Lembaran Kerja Peserta Didik (eLPKD) dengan penekanan pada tiga level representasi kimia berbasis ICT. Pengetahuan kimia dapat direpresentasikan dalam tiga cara utama yaitu makro, submikro dan simbolik yang dinamakan dengan triplet kimia [1].

Ketiga level ini lebih dikenal dengan level makroskopik, level submikroskopik dan level simbolik [2][3]. Seorang guru kimia sebaiknya mempunyai kemampuan menghubungkan keterkaitan tiga level representasi kimia untuk pemahaman konsep kimia secara utuh. Keterkaitan ini hendaknya timbal balik yang dinamakan dengan interkoneksi.

Pemahaman seseorang terhadap suatu konsep ditunjukkan oleh kemampuannya mentransfer dan menghubungkan antara level makroskopik, submikroskopik dan simbolik tersebut. Ketiga level reprensentasi ini umumnya ditemui pada buku-buku general chemistry 2010 tahun ke atas. Bukubuku tersebut dapat didownload secara bebas (free) dari web. Representasi kimia pada buku tersebut dapat dipindahkan ke LKPD. Penggunaan e-LKPD memberikan keuntungan antara lain dapat memvisualisasikan konsep-konsep abstrak, mensimulasikan proses yang sulit dilakukan secara manual, menampilkan materi pembelajaran dalam berbagai format sehingga lebih menarik dan terbaru dari berbagai sumber, memungkinkan terjadi interaksi pembelajar dan materi pembelajaran, mengatasi keterbatasan ruang, waktu dan tenaga, mendukung perubahan peran guru ke arah fasilitator dan mediator [4].

LKPD telah digunakan oleh beberapa guru-guru kimia di SMAN Kabupaten
Padang Pariaman tetapi belum berbentuk eLKPD yang berorientasi pada tiga level representasi kimia dan hubungan timbal balik antara tiga level tersebut. Hubungan ketiga level representasi ini sangat penting untuk pemahaman konsep kimia secara utuh [1]. Tiga level representasi kimia dapat berfungsi sebagai wahana untuk memfasilitasi terjadinya belajar bermakna. Pemahaman siswa juga dapat dikembangkan dengan pembelajaran menggunakan tiga level representasi dan menginterkoneksikan ketiga level representasi tersebut [5]. Penggunaan tiga level representasi kimia dan interkoneksinya pada e-LKPD adalah sangat penting dalam pembelajaran agar pemahaman siswa terhadap suatu konsep menjadi lebih baik sehingga terbentuk model mental yang utuh [6]. Model mental yang utuh akan menghasilkan ketrampilan berfikir tingkat tinggi, Higher Order Thingking Skills (HOTS). Keterampilan ini sangat diperlukan untuk menyongsong abad 21 [7].

Selain itu, penyajian materi kimia yang dibuat beberapa guru belum terstruktur dengan baik dan belum sesuai dengan model pembelajaran yang disarankan kurikulum 2013. Penyajian konsep mol dalam bentuk modul berbasis inkuiri terstruktur dengan penekanan pada tiga level representasi kimia telah dikembangkan dengan tingkat kevalidan yang sangat tinggi [8]. LKPD yang dibuat guru hendaknya berbasis model pembelajaran yang sesuai kurikulum 2013. LKPD hendaknya mudah diakses siswa. Oleh sebab itu, LKPD diubah menjadi e-LKPD agar siswa dapat mendownload dan menggunakannya seperti buku sesungguhnya. Keunggulan e-LKPD ini adalah dapat dilengkapi dengan vidio pembelajaran, animasi dan musik. Keterampilan ini belum dimiliki oleh sebagian besar guru kimia di SMAN Kecamatan Padang Pariman. Oleh sebab itu, pelatihan pembuatan e-LKPD menggunakan Flip Book Maker dengan 
penekanan pada tiga level representasi kimia diperlukan bagi guru-guru tersebut.

Masalah yang dihadapi oleh guru-guru kimia di SMAN Kabupaten Padang Pariaman adalah kurangnya pengetahuan dan keterampilan penggunaan ICT sebagai sumber belajar serta kurangnya penggunaan tiga level representasi kimia untuk pembuatan LKPD berbasis ICT dengan menggunakan tiga level representasi kimia. Pemahaman seseorang terhadap ilmu kimia akan semakin baik apabila mampu menghubungkan ketiga level tersebut [10]. Kemampuan ini sangat diperlukan bagi seorang guru. Pemahaman konsep kimia yang baik/utuh akan menghasilkan model mental kimia yang benar pada siswa.

Pengubahan LKPD menjadi e-LKPD menggunakan software Kvisoft Flip Book Maker mempunyai beberapa keunggulan yaitu dapat dimasukkan vidio pembelajaran, media animasi dan musik. Guru-guru kimia di SMAN Kabupaten Padang Pariaman belum mengenal Kvisoft Flip Book Maker (ketua MGMP kimia SMAN Kabupaten Padang Pariaman, 2019). Kvisoft Fli pBook Maker Pro adalah software untuk membuat sebuah e-book. Penggunaan software ini cukup mudah.

Tujuan kegiatan pengabdian meningkatkan kompetensi guru menggunakan e-book general chemistry standar dan vidio pembelajaran kimia pada situs web di internet dan memadukan sumber belajar tersebut untuk pembuatan e-LKPD menggunakan flip book maker dengan penekanan pada tiga level representasi kimia.

\section{Metoda yang digunakan}

Metode yang digunakan untuk pelaksanaan Program Kemitraan Masyarakat (PKM) adalah ceramah, demonstrasi dan workshop. Metoda ceramah dan demonstrasi digunakan untuk menyampaikan materi terminologi ICT dan internet, tiga level representasi kimia dan Revolusi Industri 4.0.
Metoda ceramah dan praktek digunakan untuk mendownload buku general chemistry dan vidio pembelajaran kimia. Praktek meliputi trik cepat mengedit gambar dari buku general chemistry dan memindahkan ke LKPD. Workshop membuat e-LKPD mengguna-kan flip book maker, e-LKPD disertai vidio pembelajaran, dan gambar animasi.

Setiap peserta dibimbing langsung oleh instruktur yang ahli dibidangnya. Praktek dilakukan oleh setiap peserta untuk mengubah LKPD menjadi e-LKPD yang dilengkapi dengan vidio pembelajaran dan animasi kimia. Pemateri pada pengabdian ini adalah empat orang dosen. Kegiatan pengabdian ini dibantu oleh tiga orang mahasiswa yaitu dua orang mahasiswa S2 bimbingan dosen yang tugas akhirnya adalah pembuatan e-modul dan e-LKPD berbasis inkuiri terstruktur dengan penekanan pada tiga level representasi kimia, sedangkan satu mahasiswa dengan tugas akhir pembuatan modul dengan memuat tiga level representasi kimia.

\section{Hasil dan Diskusi \\ Hasil sebagai Proses}

Pelatihan pembuatan e-LKPD mengguna-kan flip book maker dengan penekanan pada tiga level representasi kimia telah dilakukan untuk guru kimia SMA Negeri di Kabupaten Padang Pariaman. Pelatihan diadakan di SMAN1 Batang Anai, Pariaman. Hasil kegiatan pengabdian kepada masyarakat dapat dilihat dari aspek hasil sebagai proses dan aspek hasil sebagai pencapaian tujuan. Tujuan pengabdian tercapai tergantung pada proses kegiatan pengabdian yang dilakukan. Kegiatan pengabdian diamati selama berlangsung. Guru-guru sebagai peserta pengabdian mengikuti kegiatan dengan sungguhsungguh (Gambar 1). 


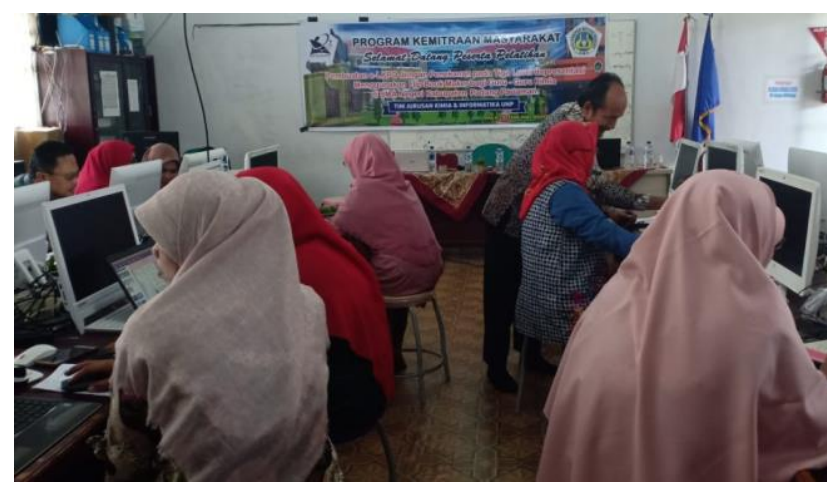

Gambar 1. Perserta sedang mengikuti pelatihan pembuatan e-LKPD dengan penekanan pada tiga level representasi kimia.

Evaluasi hasil sebagai prosess dilakukan terhadap beberapa aspek yaitu: aspek relevansi, efektifitas, tanggapan dan keseriusan peserta selama pelatihan, keterampilan peserta melakukan praktek, tindak lanjut dan pentingnya materi pengabdian. Tanggapan, keseriusan dan keteram-pilan peserta diketahui melalui pengamatan langsung, wawancara dan foto.

a. Relevansi

Kegiatan pengabdian kepada masyarakat ber kaitan dengan tujuan pengabdian. Kegiatan pengabdian meningkatkan pengetahuan dan keterampilan guru-guru kimia menggunakan sumber belajar pada situs web terutama situs yang berkaitan dengan buku dan animasi. Kegiatan pengabdian ini dapat meningkatkan keterampilan guru-guru kimia memindahkan gambar pada e-book general chemistry ke LKPD di microsoft dengan penekanan pada tiga level representasi kimia.

b. Efektivitas

Semua materi pengabdian yang telah diberikan cukup efektif digunakan untuk mencapai tujuan pengabdian. Guru-guru tersebut merasakan manfaat yang telah diberikan karena belum pernah memperoleh pelatihan pembuatan e-LKPD menggunakan flip book maker dengan penekanan pada tiga level representasi kimia sebelumnya.

c. Tanggapan dan keseriusan
Tanggapan peserta pengabdian sangat positip. Hal ini dapat dilihat dari hadirnya guru kimia, peserta mengikuti pengabdian dengan serius, peserta banyak mengajukan pertanyaan. Peserta aktif mendownload $e$ book chemistry standar dan vidio pembelajaran, memadukan sumber balajar pada LKPD di microsoft. Pada pertemuan kedua peserta memperlihatkan e-LKPD yang telah dibuat, mendiskusikan urutan penyajian dan kebenaran keilmuannya.

d. Keterampilan peserta melakukan praktek

Peserta diberi contoh dan dilatih mendownload e-book general chemistry standar dari bookfi dan vidio pembelajaran kimia dari Yuotube, menggunakan snipping tools untuk memindahkan gambar atau tabel dari e-book general chemistry dan mengeditnya, menata materi secara terstruktur, dan memasukkan vidio pembelajaran atau animasi ke e-LKPD.

e. Tindak lanjut

Tindak lanjut dilakukan pada 25 September 2019 dengan melihat e-LKPD peserta. Peserta yang hadir dua hari pengabdian dan membuat e-LKPD dengan penekanan pada tiga level reprentasi kimia memperoleh sertifikat. Peserta diharapkan mengembangkan pengetahuan dan keterampilan yang telah diperolehnya untuk diberikan kepada guru-guru di SMA/MA lainnya.

f. Pentingnya materi pengabdian

Informasi pentingnya materi pengabdian yang telah diberikan diperoleh melalui angket. Respon peserta terhadap materi yang telah diberikan adalah sangat perlu (Tabel 1). Dengan demikian materi pengabdian yang telah disampaikan sangat diperlukan peserta.

Tabel 1.Respon peserta terhadap materi. 


\begin{tabular}{|c|c|c|}
\hline Materi & Respon peserta & Jumlah respor \\
\hline Penggunaan intemet sebagai sumber belajar & $\begin{array}{l}\text { Sangat perlu } \\
\text { Perlu } \\
\text { Kurang perlu } \\
\text { Tidak perlu }\end{array}$ & 21 \\
\hline $\begin{array}{l}\text { Penggunaan intemet untuk mencari sumber belajar } \\
\text { dalam bentuk buku(e-book standar) }\end{array}$ & $\begin{array}{l}\text { Sangat perlu } \\
\text { Perlu } \\
\text { Kurang perlu } \\
\text { Tidak perlu }\end{array}$ & 21 \\
\hline $\begin{array}{l}\text { Penggunaan intemet untuk mencari sumber belajar } \\
\text { dalam bentuk animasi dan video }\end{array}$ & $\begin{array}{l}\text { Sangat perlu } \\
\text { Perlu } \\
\text { Kurang perlu } \\
\text { Tidak perlu }\end{array}$ & $\begin{array}{l}20 \\
1\end{array}$ \\
\hline $\begin{array}{l}\text { Pembuatan e-LKPD dengan penekanan tiga level } \\
\text { reprentasi kimia }\end{array}$ & $\begin{array}{l}\text { Sangat perlu } \\
\text { Perlu } \\
\text { Kurang perlu } \\
\text { Tidak perlu }\end{array}$ & $\begin{array}{l}19 \\
2\end{array}$ \\
\hline $\begin{array}{l}\text { Memasukkan vidio pembelajaran dan animasi pada } \\
\text { e-LKPD }\end{array}$ & $\begin{array}{l}\text { Sangat perlu } \\
\text { Perlu } \\
\text { Kurang perlu } \\
\text { Tidak perlu }\end{array}$ & $\begin{array}{l}16 \\
5\end{array}$ \\
\hline
\end{tabular}

\section{Hasil sebagai Pencapaian Tujuan}

Peningkatan pengetahuan dan keterampilan guru diukur sebelum dan setelah dilakukan pelatihan. Aspek yang diukur diberi skor oleh peserta adalah konsep-konsep yang berkaitan dengan pembuatan e-LKPD kimia berbasis ICT dengan penekanan pada level makro, submikro dan simbolik. Konsep-konsep pada aspek tersebut tersebut meliputi terminologi ICT, model mental dan cara mengukurnya, tiga level representasi kimia dan interkoneksinya, mendownload sumber belajar, memadukan sumber belajar menjadi media pembelajaran yang berorientasi pada tiga level representasi kimia. Aspek aspek yang diamati diberi skor oleh peserta (Tabel 1).

Tabel 1. Aspek yang diberi skor oleh peserta pengabdian

\begin{tabular}{|l|l|}
\hline No & Aspek yang Dinilai \\
\hline 1 & $\begin{array}{l}\text { Saya menguasai terminologi ICT (Information } \\
\text { and Communication Technology, Teknologi } \\
\text { Informasi dan Komunikasi, TIK) dan internet }\end{array}$ \\
\hline 2 & $\begin{array}{l}\text { Saya menguasai Teknologi Informasi dan } \\
\text { Komunikasi untuk pembelajaran pada era } \\
\text { Revolusi Industri 4.0 }\end{array}$ \\
\hline 3 & $\begin{array}{l}\text { Saya dapat mendownload e-book general } \\
\text { chemistry yang dapat dijadikan sumber belajar } \\
\text { bagi guru }\end{array}$ \\
\hline 4 & $\begin{array}{l}\text { Saya dapat memotong dan memindahkan } \\
\text { gambar dari e-book general chemistry pada } \\
\text { LKPD menggunakan Snipping tool atau Snap }\end{array}$ \\
\hline
\end{tabular}

\begin{tabular}{|l|l|}
\hline 5 & $\begin{array}{l}\text { Saya dapat mengedit gambar dari e-book } \\
\text { chemistry standar menggunakan paint pada } \\
\text { microsoft }\end{array}$ \\
\hline 6 & $\begin{array}{l}\text { Saya dapat mendownload vidio standar } \\
\text { pembelajaran kimia dari Youtube }\end{array}$ \\
\hline 7 & $\begin{array}{l}\text { Saya dapat mengedit vidio pembelajaran } \\
\text { kimia }\end{array}$ \\
\hline 8 & $\begin{array}{l}\text { Saya dapat mendownload gambar bergerak } \\
\text { animasi) pada google }\end{array}$ \\
\hline 9 & Saya memahami tiga level representasi kimia \\
\hline 10 & Saya memahami Level makroskopik \\
\hline 11 & Saya memahami Level submiskrosopik \\
\hline 12 & Saya memahami Level simbolik \\
\hline 13 & $\begin{array}{l}\text { Saya dapat menginterkoneksikan level } \\
\text { makroskopik, sub-mikroskopik dan simbolik } \\
\text { dalam pembelajaran }\end{array}$ \\
\hline 14 & $\begin{array}{l}\text { Saya dapat menggunakan tiga level } \\
\text { representasi kimia dalam LKPD }\end{array}$ \\
\hline 15 & Saya memahami konsep model mental siswa \\
\hline 16 & $\begin{array}{l}\text { Saya mengetahui cara mengukur model } \\
\text { mental siswa }\end{array}$ \\
\hline 17 & $\begin{array}{l}\text { Saya memahami kaitan model mental siswa } \\
\text { dengan tiga level representasi kimia }\end{array}$ \\
\hline 18 & $\begin{array}{l}\text { Saya memahami keterkaitan model mental } \\
\text { siswa dengan HOTS }\end{array}$ \\
\hline 19 & $\begin{array}{l}\text { Saya dapat merubah LKPD menjadi e-LKPD } \\
\text { menggunakan flip book maker }\end{array}$ \\
\hline 20 & $\begin{array}{l}\text { Saya dapat memasukkan vidio pembelajaran, } \\
\text { gambar animasi pada e-LKPD menggunakan } \\
\text { flip book maker }\end{array}$ \\
\hline &
\end{tabular}

Guru-guru yang menjadi peserta dalam pelatihan menilai pengetahuan dan kemampuan-nya sendiri sebelum dilaksanakan pelatihan pembuatan e-LKPD menggunakan flip book maker dengan pendekatan pada tiga level representasi kimia yaitu makro, submikro dan simbolik. Sebagian besar peserta masih mengalami kendala dalam menguasai terminologi ICT dan internet. Peserta pelatihan belum memahami tiga level representasi kimia dan interkoneksinya dengan baik. Sebagian besar peserta pelatihan juga belum menguasai cara mendownload e-book general chemistry standar, video pembelajaran kimia, dan gambar animasi dengan baik, sehingga peserta mengalami kesulitan membuat e- 
LKPD berbasis ICT dengan penekanan pada tiga level representasi kimia. Beberapa peserta mampu mendownload sumber belajar untuk pembuatan LKPD, namun LKPD yang dibuat belum memuat tiga level representasi kimia.

Secara umum semua peserta telah memperoleh kemajuan jika dibandingkan sebelum diadakan pelatihan. Sebagian besar peserta telah mengalami kemajuan menguasai terminologi ICT meskipun masih ada beberapa peserta yang belum menguasai terminologi ICT secara tepat. Peserta juga telah memahami tiga level representasi dan dapat menginterkoneksikan ketiga level representasi tersebut dengan baik. Peserta juga telah menguasai cara mendownload ebook, video, dan gambar animasi. Peserta juga telah dapat memadukan sumber belajar tersebut pada e-LKPD dengan penekanan pada tiga level representasi kimia. Aspek yang diberi skor oleh peserta pengabdian sebelum dan setelah pelatihan dinyatakan sebagai $\%$ penguasaan. Persentase penguasaan terhadap 20 point yang pada Tabel 1 oleh guru-guru sebelum dan setelah pelatihan dimuat pada Gambar 2.

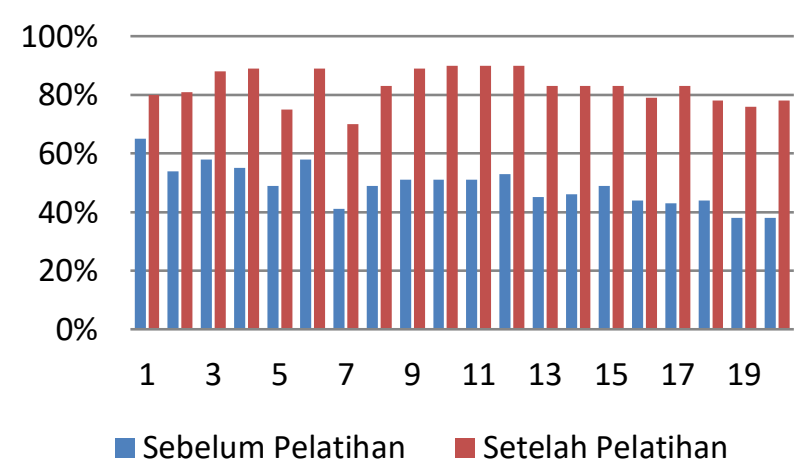

Gambar 2. Peningkatan pengetahuan guru sebelum dan setelah dilakukan pelatihan.

\section{Kesimpulan}

a. Kegiatan pengabdian ini dapat meningkatkan pengetahuan dan keterampilan guru-guru kimia dalam menggunakan e-book general chemistry standar dan vidio pembelajaran kimia pada situs web di internet.

b. Kegiatan pengabdian dapat meningkatkan pengetahuan dan keterampilan guru-guru kimia dalam memadukan sumber belajar pada point pertama tersebut yang digunakan untuk pembuatan e-LKPD berbasis ICT dengan penekanan tiga level representasi kimia.

\section{Ucapan Terima Kasih}

Kegiatan pengabdian skim PKM didanai oleh DIPA Universitas Negeri Padang dengan nomor kontrak: 1359/UN35.13/PM/2019.

\section{Daftar Pustaka}

[1] Talanquer V (2010). Macro, Submicro, and Symbolic: The many faces of the chemistry "triplet". International Journal of Science Education.. 33(2): 179-195

[2] Gilbert JK, Treagust D F(2009). Multiple reprentation in chemical education, Springer

[3] Gilbert et al., 2009. Introduction: Macro, Submicro and Symbolic Representations and the Relationship Between Them: Key Models in Chemical Education. In Multiple Representation in Chemical Education, Models and Modelling in Science Education, 4: Spinger Science.

[4] Sahid (2011). Pengembangan media pembelajaran berbasis ICT pada https://www.google.co.id/\#q=pengemba ngan+media+berbasis+ict, diakses 04 Maret 2015.

[5] Jaber, L. Z \& BouJaoude, S. 2012. A Macro-Micro-Symbolic Teaching to Promote Relational Understanding of Chemical Reactions. International Journal of Science Education, 34(7): 973-998 
[6] Devetak, et al. 2009. Comparing Slovenian Year 8 \& Year 9 Elementary School Pupils' Knowledge of Electrolyte Chemistry and Their Instrisic Motivation. Chemistry Education Research and Practice, 10(4): 281-290.

[7] Direktorat Pembinaan Sekolah Dasar dan Menengah. 2017. Panduan Implementasi kecakapan abad 21 Kurikulum 2013 di sekolah menegah atas. Direktorat Jenderal Pendidakan Dasar dan Menengah Kementrian Pendiidkan dan Kebudayaan.

[8] Sagita R, Azra F, Azhar M 2018. Development of Mole Concept Module Based on Structured Inquiry with Interconection of Macro, Submicro, and Symbolic Representation for Grade X of Senior High School Conf. Ser.: Mater. Sci. $\quad$ Eng. $\quad 335 \quad 012104$ https://doi.org/10.1088/ 1757$\underline{899 X / 335 / 1 / 012104}$

[9] Istiyanto, Heri. 2013. Panduan media ajar dengan flip book maker

[10]Treagust et al., 2003. The Role of Submicroscopic and Symbolic Representa-tion in Chemical Explanations. Intrnational Journal of Science Education, 25(11): 1353-1368. 